\title{
The Impact of Transmit Diversity in LTE-A Capacity
}

\author{
Emad Aldeen Abd Allah Omer ${ }^{1}$, Mohammed Abaker Hussian ${ }^{2}$ \\ ${ }^{1}$ Alneelain University, Faculty of engineering, \\ Aljamhorya Road, Khartoum, Sudan \\ Emadmaster11[at]gemail.com \\ ${ }^{1}$ Alneelain University, Faculty of engineering, \\ Albaladya Road, Khartoum, Sudan \\ abaker2826022[at]yahoo.com
}

\begin{abstract}
Transmitter using diversity technology to increase signal quality and reduce the error in the received signal by send the same data across a number of antennas number of copies of data across more than one antenna. In this paper we aims to study the impact of Transmit Diversity on capacity for the Long Term Evolution-Advanced for normal cyclic prefix in spectrum allocation of (25, $30,35,40$ and 100) $\mathrm{MHz}$ The capacity calculations will take into account the effect of the correction factor (losses due to cyclic prefix and reference symbols). The result of study will determine whether the transmit diversity meet the requirement of IMT-Advanced that identify by The ITU in terms of capacity at acceptable value of SNR and analyze the effect of the number of antennas in capacity when using transmit diversity.
\end{abstract}

Keywords: MIMO, LTE-A, Transmit Diversity, capacity

\section{Introduction}

The limitation of bandwidth and the rapid growth of users and the continuing need to increase the data rate Led to very fast development in wireless communications systems in the past two decades, through the provision of different generations $2 \mathrm{G} 3 \mathrm{G}$ and $4 \mathrm{G}$ which now reached the LTE-A

LTE-A is a part of the 3GPP standards, in addition to the use of MIMO and OFDM it introduced many changes and improvements.

LTE-A aims to improve spectral flexibility, increase data rates, improved coverage and increase battery life time [1].

Bandwidth is one of the most important success factors in the wireless communications for that the $3 \mathrm{GPP}$ introduced carrier aggregation to increase bandwidth while maintaining compatibility with LTE r8, r9 and ensure high data rates to meet the voice and video transmission[2] The capacity determine the quality of the communication systems at the end user[3].

In September 2009 the 3GPP Partners made a formal submission to the ITU proposing that LTE Release 10 \& beyond (LTE-Advanced) should be evaluated as a candidate for IMT-Advanced.

In October of the year 2010 lte-a successfully passed the evaluation process and has been adopted As a standard for the fourth generation that achieves the ITU standard that defines the requirements must be available in the mobile systems that are part of or exceed the capabilities of IMT- 2000 or IMTAdvanced (International Mobile Telecommunications) the most important requirements of IMT-Advanced increase the data rates. In order to support advanced services and applications 100Mbps for low for low and 1Gbps for high mobility scenarios. [4] In this paper we evaluate and compare the capacity in LTE-A for Transmit Diversity (TXD 2X1) and (TXD 4X2) for normal cyclic prefix by using aggregated Carrier $(25,30,35,40$ and 100) $\mathrm{MHz}$ and analyze the effect of the number of antennas in capacity when using Transmit Diversity.

\section{Transmit diversity (TXD)}

In transmit diversity, redundant information (same data stream) is transmitted on different antennas.

2.1 Transmit diversity implements $2 \mathrm{X} 1$ (MISO)

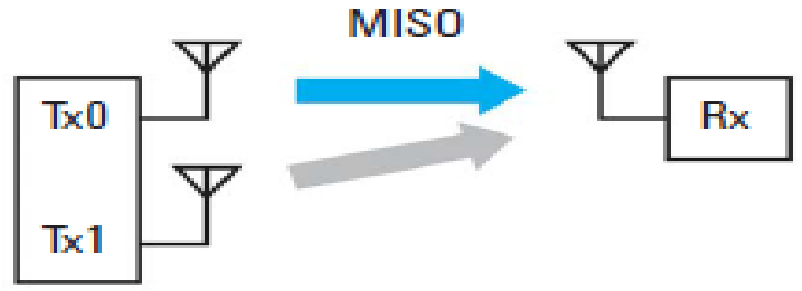

Figure 1: Multiple Input Single Output (2X1)

2.2 Transmit diversity implements 4X2 (MIMO)

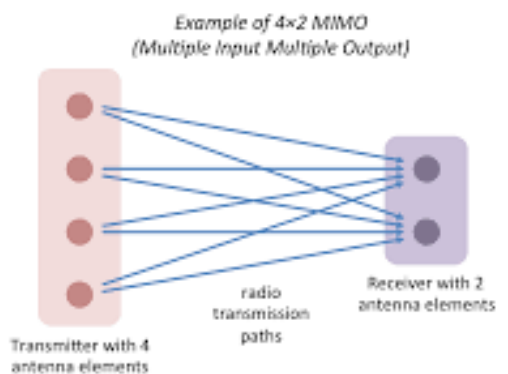

Figure 2: Multiple Input multiple Output (4X2)

\section{Volume 5 Issue 6, June 2016} www.ijsr.net 


\section{International Journal of Science and Research (IJSR) \\ ISSN (Online): 2319-7064}

Index Copernicus Value (2013): 6.14 | Impact Factor (2015): 6.391

\section{Methodology}

3.1 The general equation of Shannon's Channel Capacity:

Shannon derived the following capacity formula (1948) for an additive white Gaussian noise channel (AWGN) [5]

$$
C=w \log _{2}(1+S / N)
$$

W is the bandwidth of the channel in $\mathrm{Hz}, \mathrm{S}$ is the signal power in watts, $\mathrm{N}$ is the total noise power of the channel in watts.

3.2 capacity is[5]

3.3

$$
C=F * B \log _{2}(1+S N R)
$$

Where $\mathrm{F}$ is the correction factor, B is the effective bandwidth and SNR is the signal to noise ratio.

3.4 The effective bandwidth is:

$$
B=\frac{N_{s c} * N_{s} * N_{r b}}{T_{s u b}}
$$

Where $\mathrm{N}_{\mathrm{sc}}=12$ is the subcarriers in one $\mathrm{RB}, \mathrm{N}_{\mathrm{s}}$ is the number of OFDM symbols in one subframe (14 for normal Cyclic Prefix (CP) ), $\mathrm{N}_{\mathrm{rb}}$ is resource block that fit into the selected system bandwidth (for example $125 \mathrm{RBs}$ within a $25 \mathrm{MHz}$ system bandwidth) and $\mathrm{T}_{\text {sub }}$ is the duration of one subframe equal to $1 \mathrm{~ms}$. As it is illust For normal cyclic prefix the length of the first symbol is 5.2 microseconds while for the other six symbols the length is 4.7 microseconds.

\section{5 correction factor}

$$
F=\frac{T_{\text {frame }}-T_{c p}}{T_{\text {frame }}} * \frac{N_{s c} * \frac{N_{s}}{2}-R}{N_{S C} * \frac{N_{s}}{2}}
$$

The first part of the above equation represents the cyclic prefix loss in which $\mathrm{T}_{\text {frame }}$ is the fixed frame duration equal to $10 \mathrm{~ms}$. And $\mathrm{T}_{\mathrm{cp}}$ is the total CP time of all OFDM symbols within one frame. And the second part represents the reference symbols loss where $\mathrm{R}$ is the number of resource elements (RE) that carries the reference symbols in the antenna port, (Reference Signal $(\mathrm{R})$ is provided to enable the User Equipment (UE) to estimate the radio channel).

\section{Transmit diversity (2X1):}

4.1 the capacity for transmit diversity $2 \mathrm{X} 1$ is:

$$
C_{T X D 2 X 1}=F_{1} * B \log _{2}(1+S N R)
$$

4.2 the correction factor is:

$$
F_{1}=\frac{T_{\text {frame }}-T_{c p}}{T_{\text {frame }}} * \frac{N_{s c} * N_{s} / 2-R_{1}}{N_{s c} * N_{s} / 2}
$$

and $R_{1}$ is the number of reference symbols for two antenna ports which is shown in figure 3
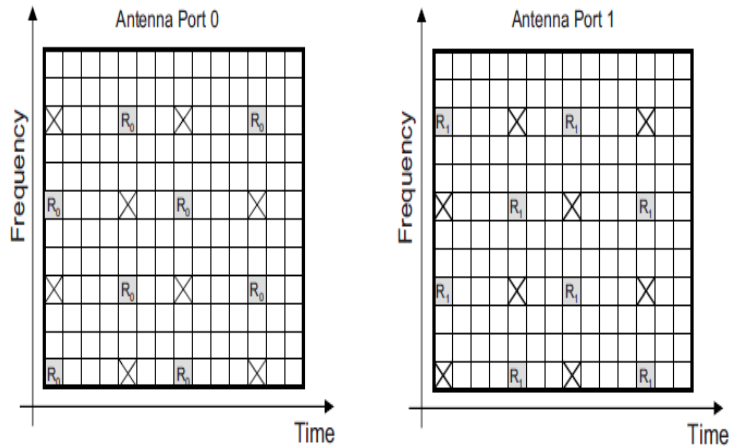

Figure 3: Cell-specific RS arrangement in the case of normal $\mathrm{CP}$ length for two antenna ports [6]

\section{Transmit diversity $4 \mathrm{X} 2$}

4.3 The capacity for transmit diversity $4 \mathrm{X} 2$ is:

$$
C_{T X D 4 X 2}=F_{2} * B \log _{2}(1+S N R)
$$

4.4 Transmit diversity $4 \mathrm{X} 2$ the correction factor is:

$$
F_{2}=\frac{T_{\text {frame }}-T_{c p}}{T_{\text {frame }}} * \frac{N_{s c} * N_{s} / 2-R_{2}}{N_{s c} * N_{s} / 2}
$$

and $R_{2}$ is the number of reference symbols for four antenna ports as in figure 4
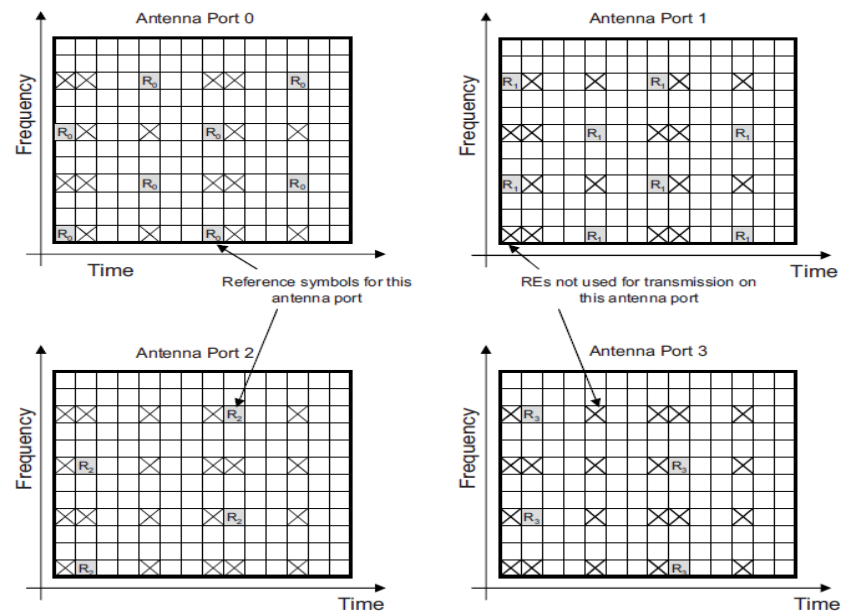

Figure 4: Cell-specific RS arrangement in the case of normal $\mathrm{CP}$ length for four antenna ports [6] 


\section{International Journal of Science and Research (IJSR) \\ ISSN (Online): 2319-7064}

Index Copernicus Value (2013): 6.14 | Impact Factor (2015): 6.391

\section{Simulation Results}

The MATLAB program used to represent the relation between Signal to Noise ratio and capacity and give a curve in In the $\mathrm{X}$ and $\mathrm{Y}$ axes to shows the relationship by using the bandwidth ( 25.30, 35, 40 and 100 ) $\mathrm{MHz}$ and the results were as in the following figures of (5 to 9):

\subsection{Simulation figures:}

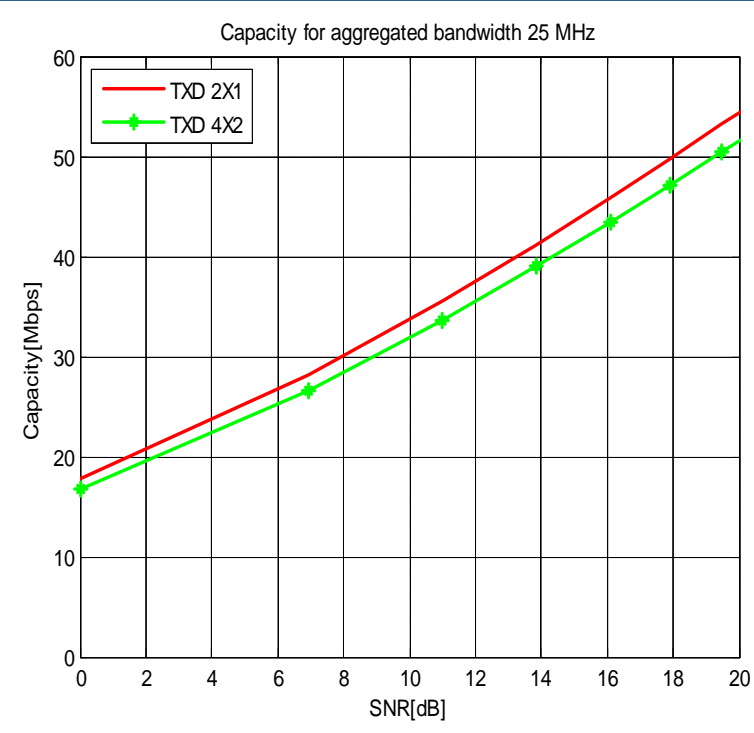

Figure 5: Capacity for $25 \mathrm{MHz}$

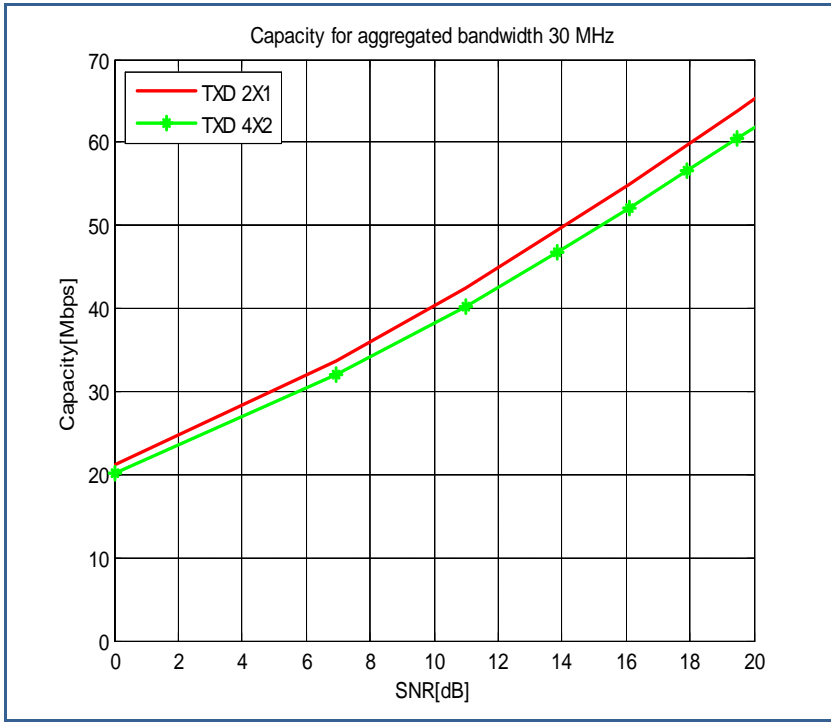

Figure 6: Capacity for $30 \mathrm{MHz}$

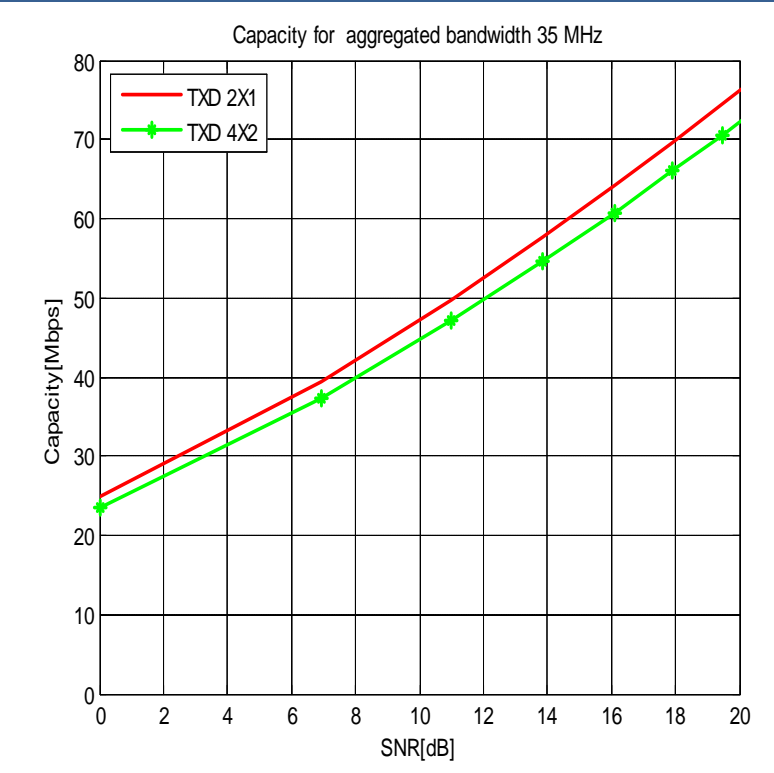

Figure 7: Capacity for $35 \mathrm{MHz}$

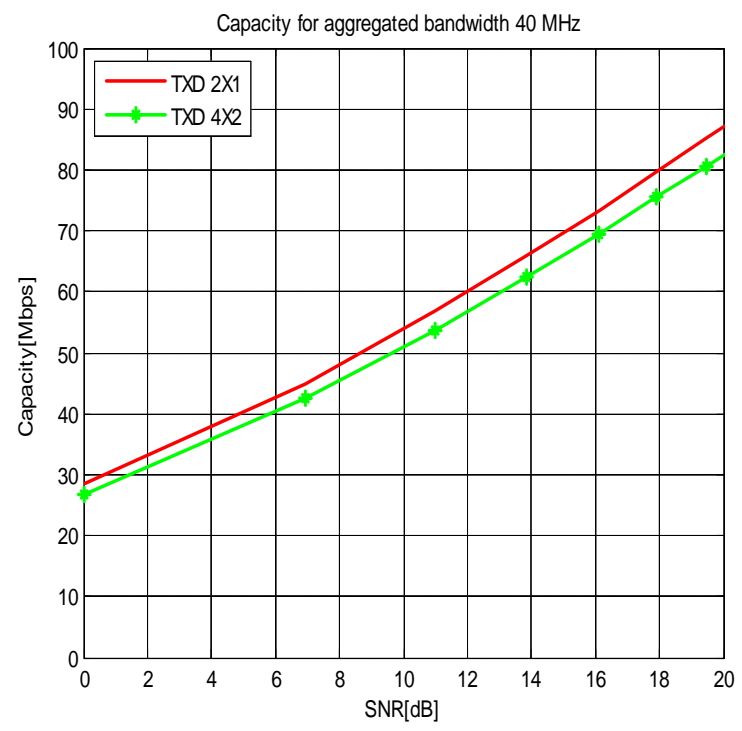

Figure 8: Capacity for $40 \mathrm{MHz}$

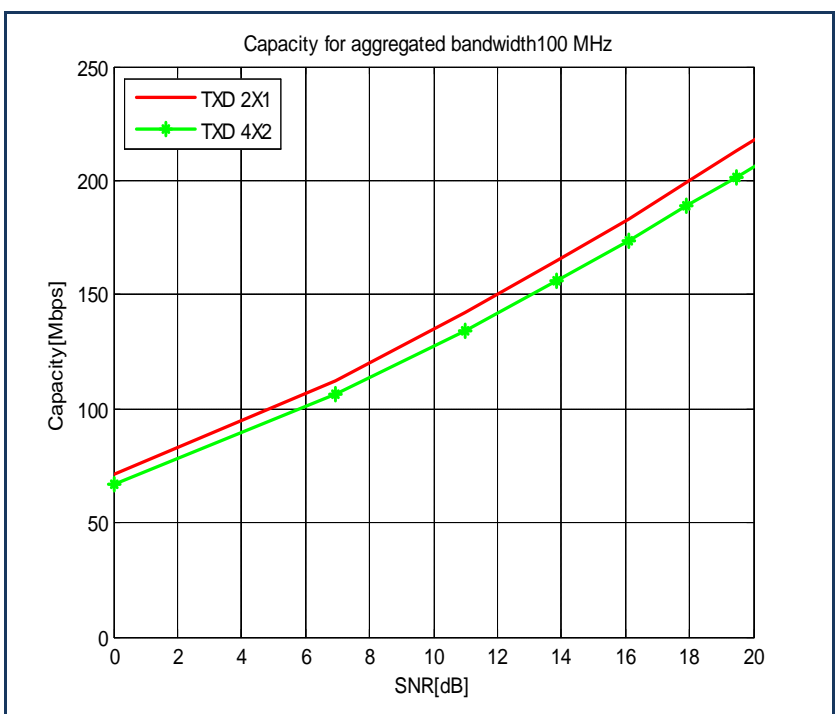

Figure 9: Capacity for $100 \mathrm{MHz}$

Volume 5 Issue 6, June 2016 www.ijsr.net 


\section{International Journal of Science and Research (IJSR) \\ ISSN (Online): 2319-7064}

Index Copernicus Value (2013): 6.14 | Impact Factor (2015): 6.391

\subsection{Capacity analysis :}

Table 1 describes capacity the results shows that TXD 2X1 gives highest capacity over TXD 4X2.

In the table a comparison is made between the two capacities at $20 \mathrm{SNR}$

Table 1: Capacity comparison in Mbps for TXD (2X1) and TXD (4X2) in all bandwidth

\begin{tabular}{|l|c|}
\hline Number of antennas & $\begin{array}{c}\text { Capacity at SNR } \\
\mathbf{1 9 . 4 6} \mathbf{~ d B}\end{array}$ \\
\hline 25 MHz & 53.19 \\
\hline TXD (2X1) & 50.39 \\
\hline TXD (4X2) & $2.8 \mathrm{Mbps}$ \\
\hline The difference & 63.83 \\
\hline 30 MHz & 60.47 \\
\hline TXD & $3.36 \mathrm{Mbps}$ \\
\hline TXD (4X2) & \\
\hline The difference & 74.47 \\
\hline 35 MHz & 70.55 \\
\hline TXD (2X1) & $3.92 \mathrm{Mbps}$ \\
\hline TXD (4X2) & 85.11 \\
\hline The difference (in Mbps) & 80.63 \\
\hline 40 MHz & $4.48 \mathrm{Mbps}$ \\
\hline TXD (2X1) & 212.8 \\
\hline TXD (4X2) & 201.6 \\
\hline The difference & $11.6 \mathrm{Mbps}$ \\
\hline 100 MHz & \\
\hline TXD (2X1) & \\
\hline TXD (4X2) & \\
\hline The difference & \\
\hline
\end{tabular}

\section{Conclusion}

For the capacity analysis for transmit diversity (2X1) versus transmit diversity (4X2) in LTE downlink, in all transmission bandwidths (25, 30, 35, 40 and 100) $\mathrm{MHz}$ for normal cyclic prefix, the simulation results show that transmit diversity (TXD 2X1) has the highest capacity over transmit diversity (TXD 4X2).

We found that, increasing in number of antennas for the transmit diversity mode reduces system capacity in all available bandwidth in LTE-A because we transmit the same data over all antennas and the process added by new antennas will increase the overhead in system.

\section{References}

[1] Andrei Vasile IORDACHE, Ion MARGHESCU, "Transmit Diversity in LTE Network", 21st Telecommunications forum TELFOR, Serbia, Belgrade, November 26-28, 2013.

[2] http://www.3gpp.org/technologies/keywordsacronyms/101-, "carrier-aggregation-explained", 2016.

[3] Kritika Sengar1, Nishu Rani1, Ankita Singhal1, Dolly Sharma2, Seema Verma1, Tanya Singh2," Study and Capacity Evaluation of SISO, MISO and MIMO RF Wireless Communication Systems", International Journal of Engineering Trends and Technology (IJETT) Volume 9 Number 9 - Mar 2014.
[4] M. Kottkamp, A. Roessler, J. Schlienz 08.20121MA169_3E LTE-Advanced Technology Introduction, 2012.

[5] C.E. Shannon, R.G. Gallager, and E.R. Berlekamp, "Lower bounds to error probabilities for coding on discrete memoryless channels" Inform. Contr., vol. 10, 1967.

[6] S. Sesia, I. Toufik, and M. Baker, "LTE the UMTS Long Term Evolution: From Theory to Practice", John Wiley \& Sons, 2011.

\section{Author Profile}

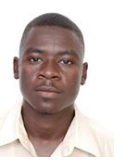

Emad aldeen Abd Allah Omer received the B.S. and M.S. degrees in Electrical Engineering computer Engineering specialize from alzaiem alazhary university in 2009 and attended for M.S.c degrees in Data and Communication Network in Alneelain University and in 2014.

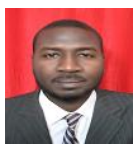

Mohammed Abaker Hussian Adam, Doctor of Philosophy $(\mathrm{PhD})$ in Electric and Electronic Engineering (Communications), University of $\mathrm{AL}$ Neelain, Sudan 2015. Master of Science (MSc) in Electric and Electronic Engineering (Telecommunication and Information Systems) University of Khartoum, Sudan, 2007. (Bsc). (Honor) of Electronic engineering (Communication) University of AL Neelain, Sudan, September 2002. 